\title{
Limitation in the use of spectral analysis to detect Weligama Coconut Leaf Wilt Disease affected palms in Southern Sri Lanka
}

\author{
A. D. Nainanayake ${ }^{1 *}$, J. Gunathilake ${ }^{2}$, M. D. P. Kumarathunga ${ }^{1}$ N. P. M. Gunawardena ${ }^{2}$ \\ and H. T. R. Wijesekara ${ }^{3}$ \\ ${ }^{\text {I} P l a n t ~ P h y s i o l o g y ~ D i v i s i o n, ~ C o c o n u t ~ R e s e a r c h ~ I n s t i t u t e, ~ L u n u w i l a, ~ 61150, ~ S r i ~ L a n k a . ~}$ \\ ${ }^{2}$ Department of Geology, Faculty of Science, University of Peradeniya, Peradeniya, Sri Lanka. \\ ${ }^{3}$ Crop Protection Division, Coconut Research Institute, Lunuwila, Sri Lanka. \\ *Corresponding Author:A.D. Nainanayake,Email: athulasl@yahoo.com
}

\begin{abstract}
Weligama Coconut Leaf Wilt Disease (WCLWD) was first reported in late 2006 in the Weligama Divisional Secretariat Division (DSD) in Matara District in the Southern Province of Sri Lanka. Surveys conducted in 2012 revealed that 65,838, 251,980 and 14,344 palms affected by the disease in Galle, Matara and Hambantota districts respectively. It has been confirmed by the Coconut Research Institute that the disease is caused by a phytoplasma which has some resemblance to the phytoplasma of Coconut Root (Wilt) disease in India. A $3 \mathrm{~km}$ wide boundary was demarcated covering the area affected by the disease and all suspicious palms were removed in the boundary zone. In the core area, affected palms were gradual removed. The disease prevailing area spanned $>680 \mathrm{~km}^{2}$ and the detection of affected coconut palms across such a large area became practically difficult. Therefore, the objective of the present study was to find alternative methods to detect affected coconut palms with yellowing leaves prominent at the middle stage of the disease, using multispectral satellite images of $0.5 \mathrm{~m}$ resolution. It was envisaged to use this technique as a supportive management tool at field level, if successful.
\end{abstract}

Normalized Differential Vegetation Index (NDVI) which is the standard and widely used algorithm for detecting vegetation under stress conditions did not reveal an appreciable isolation of canopies of affected coconut palms. Of the different customized algorithms tested, the best outcome was obtained by the algorithm (Red + Green) $-2 \times$ (Blue). When this algorithm was applied to the multispectral satellite images of $0.5 \mathrm{~m}$ resolution in the affected area, adult coconut palms in advanced stage of the disease could be distinguished with an accuracy of above $80 \%$. However, a detection of palms in the early stages of the disease where leaf flaccidity is the major morphological symptom could not be made with an acceptable level of accuracy. Moreover, the detection of affected coconut seedlings was much more difficult. Thus, only an overall accuracy of $60-70 \%$ could be achieved by this approach with multispectral satellite images of $0.5 \mathrm{~m}$ resolution. Although the level of accuracy is not sufficient for a comprehensive field level application, there is scope for further improvement using images with higher resolution.

Key words.: Phytoplasma, Multi spectral imaging, Remote sensing 


\section{INTRODUCTION}

Coconut, one of the indispensable crops in Sri Lanka, has a history going back to $300 \mathrm{BC}$ (Anon, 1949). Planting of coconut by King Aggabodi around 589 A.D. is reported in the ancient chronicle, Mahawansa, indicating the recognition that coconut has received even in ancient times. Although coconut and coconut based products have been an indispensable part of the Sri Lankan culture over the ages, cultivation of coconut at commercial level started much later and it was mainly due to the use of coconut oil for the manufacture of soap (Child, 1974).

According to the Census and Statistics (2002), the land area under coconut is 394,386 ha being second only to rice. It is grown predominantly in the Western, North-Western and Southern provinces of the island. The area coming under Kurunegala, Puttalam and Gampaha districts which is known as the "Coconut Triangle" covers approximately $56 \%$ of the total coconut growing lands of the country. The Southern province and the other non-traditional areas of the NorthCentral, Northern and Eastern provinces are the other areas under coconut. When the coconut cultivation in the Southern province is considered, the extent under coconut in Galle, Matara and Hambantota are 12,543 ha, 14,398 ha and 20,733 ha respectively, which amounts to about $6 \%$ of the total extent under coconut in the country (Census and Statistics, 2002).

Weligama Coconut Leaf Wilt Disease (WCLWD) was first reported in late 2006 in the Weligama Divisional Secretariat Division (DSD) in Matara District in the Southern Province of Sri Lanka (Everard, 2013). The early detectable foliar symptom of the disease is the loss of the angular shape of leaflets and as a result the leaf lamina becomes flattened and is termed leafflaccidity (Wijesekara and Fernando, 2013). Intense, uneven yellowing of lower and middle whorl fronds is the most striking feature of this disease (Fig. 1). Necrosis or the drying of leaflets starting from the margin or tip of such leaflets can also occur at a later stage. The disease symptoms are basically similar to that of Root (Wilt) disease (Kerala Wilt Disease) in India which has been confirmed as a phytoplasma borne disease (Sasikala et al., 1998). According to surveys conducted at a later stage by the Coconut Research Institute of Sri Lanka (CRISL) and the Coconut Cultivation Board (CCB), the number of palms affected by the disease were $65,838,251,980$ and 14,344 in Galle, Matara and Hambantota districts respectively (Everard, 2013). Research findings have confirmed that the disease condition of WCLWD is associated with a phytoplasma which is microscopic in nature (Perera et. al., 2012). At present, no treatment has been identified for diseases caused by phytoplasma.

WCLWD is a debilitating disease which persists in the palm until the death of the palm. The disease spreads to other palms through phloem feeding insects such as plant hoppers and lace bugs (Kumara et al., 2013). The disease causing Phytoplasma weakens the affected palm, reduces the production capacity (Nainanayake and Ranasinghe, 2013) and predisposes the palm to leaf rot disease caused by saprophytic fungi. This results in the rapid decline of the palm and subsequent death, if this secondary cause is not properly managed (Wijesekara and Fernando, 2013). 

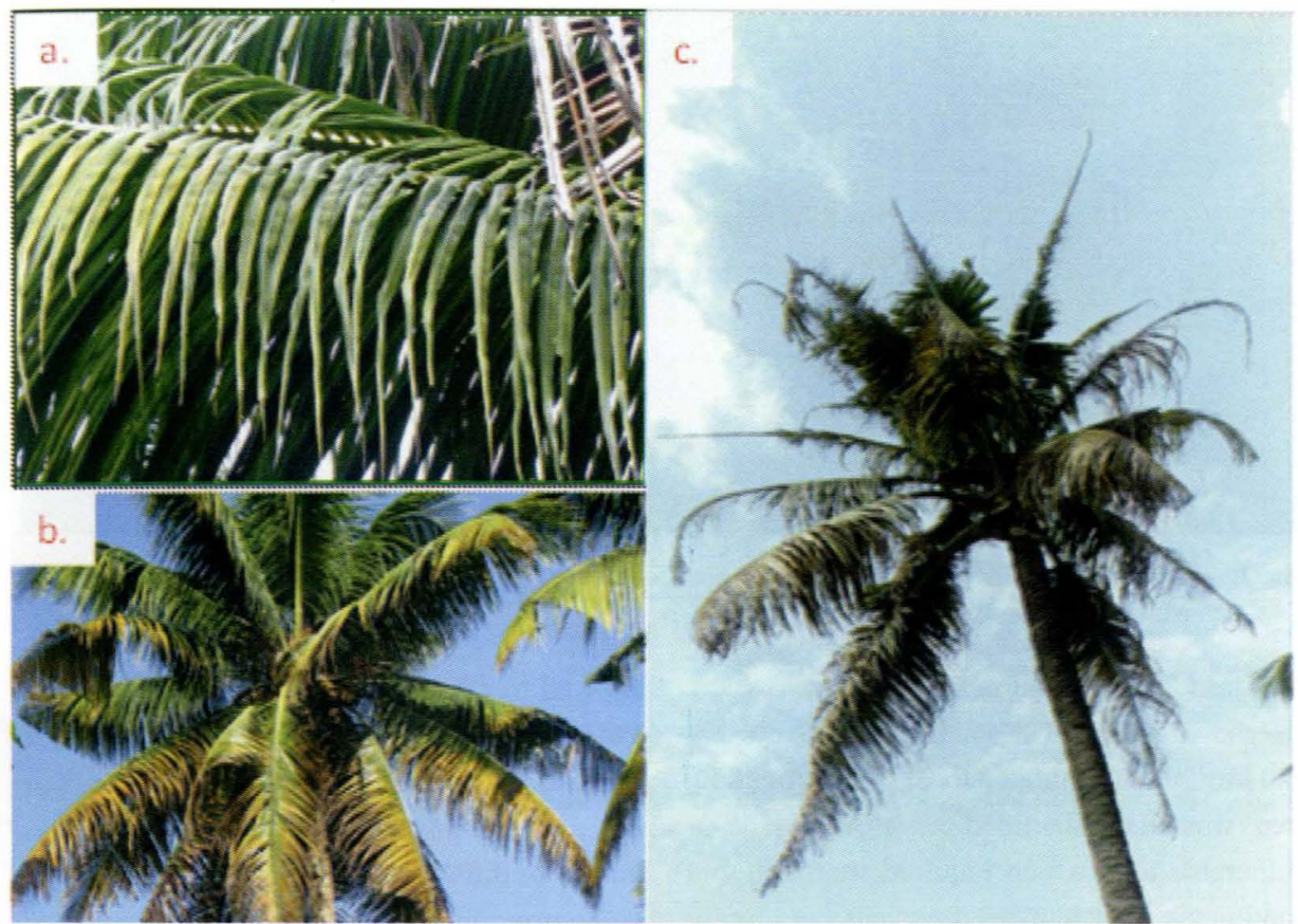

Fig. 1. Common morphological symptoms seen in WCLWD affected palms (a) Leaf flaccidity (b) intense leaf yellowing along with leaf flaccidity (c) Leaf rot affected palm.

Measures were taken by the CRISL for in-depth studies on various aspects of the disease such as disease diagnosis, symptom identification and categorization, epidemiology, identification of likely vectors and transmission pathways, agronomic and socio economic aspects of the disease. In addition, actions were also taken to prevent further spreading of the disease into other coconut growing areas. Accordingly, the disease prevalent area was identified through a field survey. A boundary was defined covering the affected area which stretched from Galle to Tangalle, along the coastal belt passing the areas viz.Angulugaha, Imaduwa, Akuressa, Kamburupitiya, Kirinda-Puhulwella, Hakmana, Walasmulla and Beliatta on the land side, along the A17 route (Fig. 2). The major road system passing above areas was used as the periphery of the disease prevalent area. A three-kilometer wide boundary was identified: $2 \mathrm{~km}$ inside and $1 \mathrm{~km}$ outside the demarcated road. All the affected and suspected palms within this 3 $\mathrm{km}$ wide boundary were constantly monitored based on morphological symptoms. Affected palms were removed to maintain a disease free boundary zone, as far as possible. This removal of affected palms was conducted in the highly affected area with emphasis on severely affected and leaf rot affected palms in the first round. Moreover, measures were taken by CRI and CCB to declare WCLWD and Leaf Rot Disease causing agents as quarantined pests by the Gazette notification No. 1542/7 (24 March 2008). This prohibited the transportation of any palm species and their live parts out of the demarcated boundary in order to prevent further spreading. 


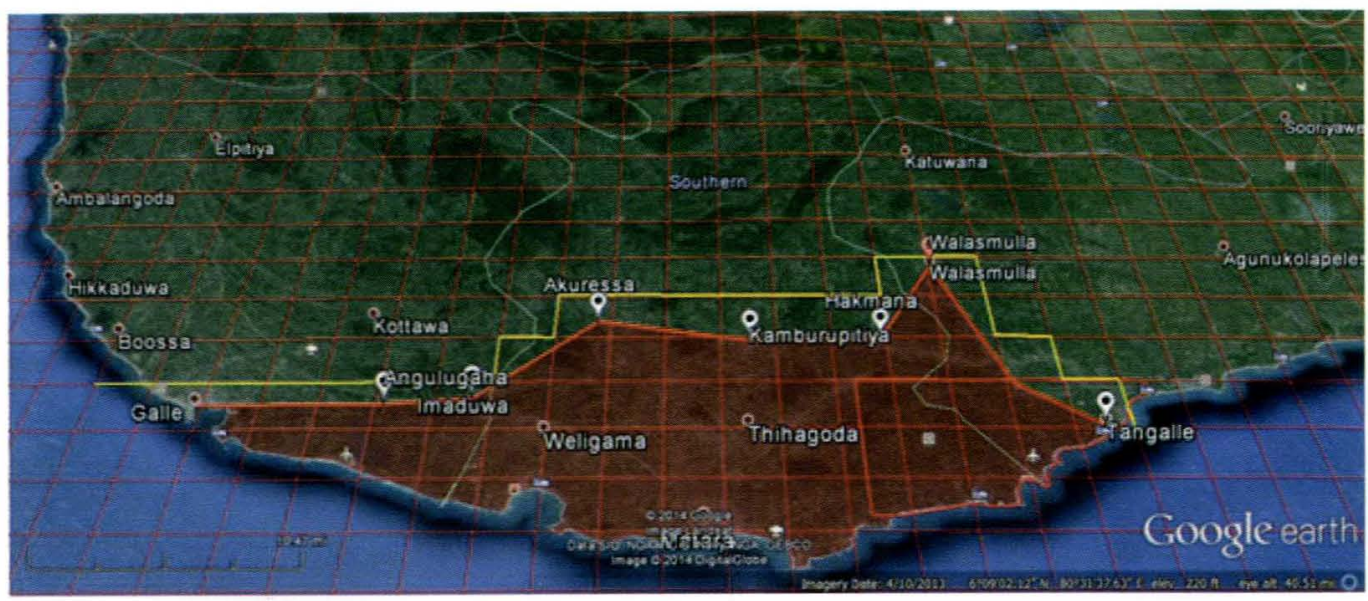

Fig. 2. Map showing identified disease prevalent demarcated area and the boundary of Galle, Matra and Hambantota districts.

The identified and demarcated area where disease was prevalent spanned approximately $680 \mathrm{~km}^{2}$. A substantial part of the surrounding area was also identified as a high risk or vulnerable area which required thorough and continuous surveillance to prevent the disease from spreading beyond the affected area. A palm to palm survey covering the entire area and the need for such repetitive ground surveys to identify recurrence and for more comprehensive removal of affected palms was a great challenge for this control program. It needed much man power and time to cover the entire area. Under these circumstances, an attempt was made to detect affected palms with yellowing leaves (which is one of the prominent morphological symptoms at the middle stage of the disease) using high resolution satellite images of the area to be used as a supportive tool for the identification of affected coconut palms.

The technique of remote sensing is defined as the acquisition of information about an object or phenomenon, without making any physical contact with the object. In this aerial sensor technology, the electromagnetic radiation emitted by the sun or a specific satellite is allowed to fall on the targeted surfaces on the earth and the reflected radiation from those surfaces is captured by the satellite, aircraft or any platform positioned in the atmosphere, as images of different wavelengths (Fig. 3). In the modern world this technology is widely used in relation to different disciplines to detect and classify objects on earth i.e. on the surface, in the atmosphere or in the ocean.

The objectives of the present study was to detect affected coconut palms with leaf yellowing (prominent at the middle stage of the disease) using remotely sensed high resolution satellite images in the Weligama area to be used as a supportive management tool (Fig. 4). Although WCLWD is not the only cause for leaf yellowing, the identification of palms with such canopies at the primary stage would significantly ease the detection process and after which diagnosis can be confirmed through RTPCR method developed by the CRI. 


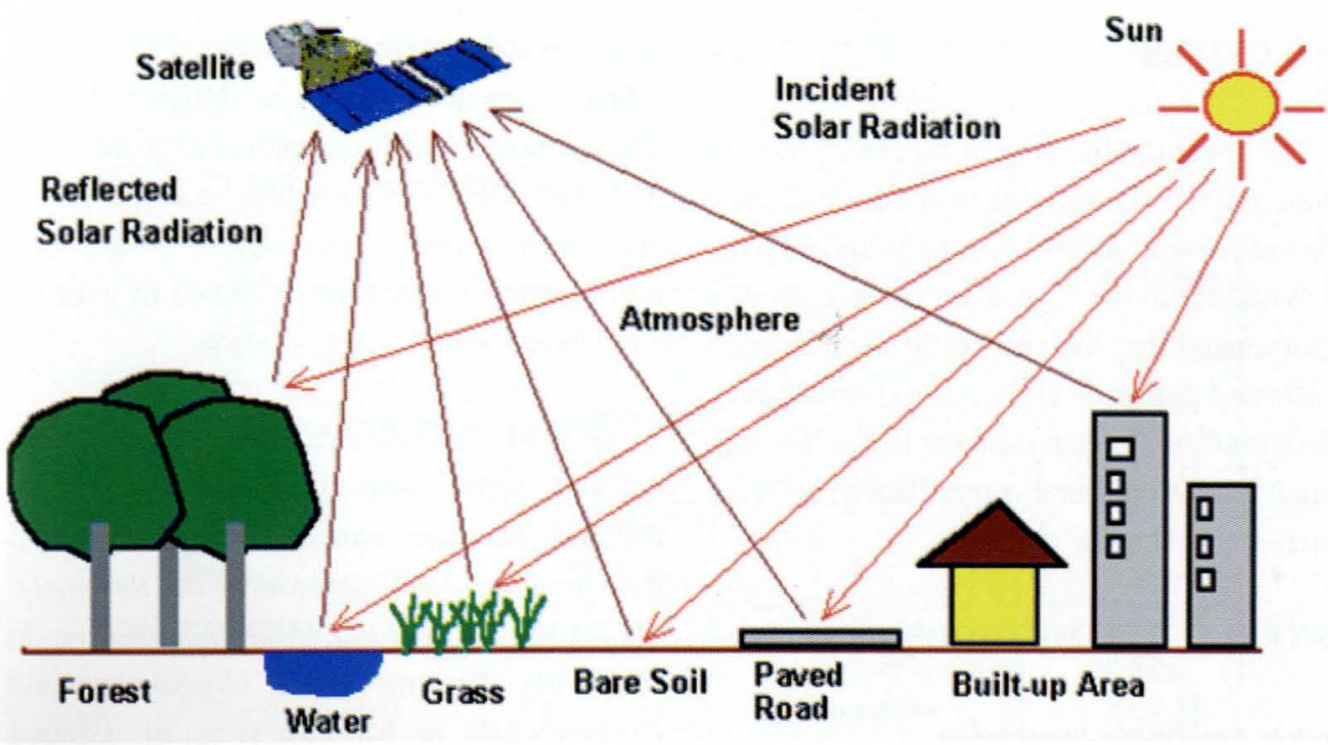

Fig. 3. The basic mechanism of remote sensing technology. The emitted electromagnetic radiation of the sun falls on different objects on the earth and is reflected back to the atmosphere. It is captured by the distantly placed satellite as images of different wave lengths.

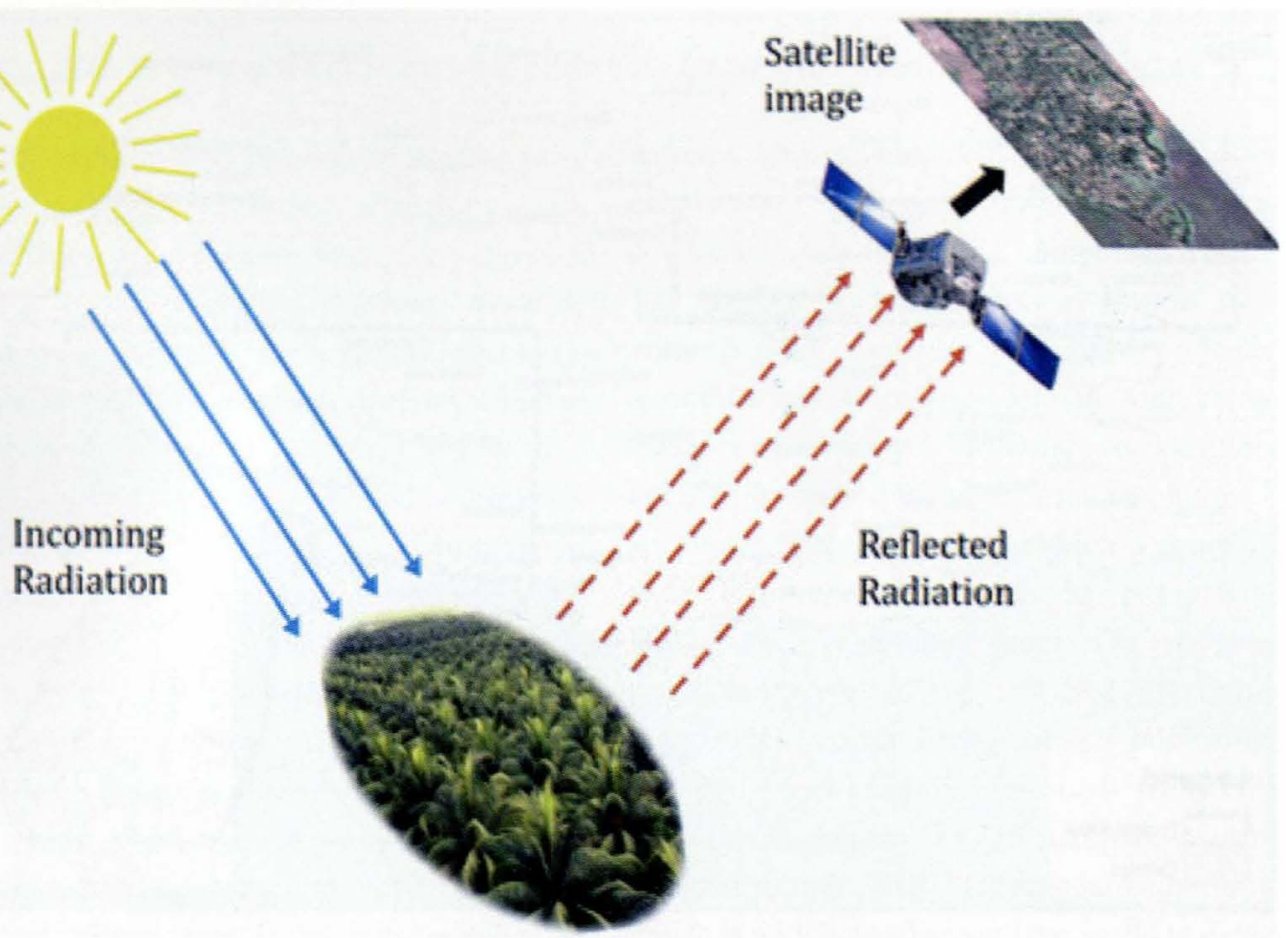

Fig. 4. An illustration of the remote sensing approach used in the study. 


\section{OBJECTIVES}

The specific objective of this study was to develop a GIS based tool to detect WCLWD affected coconut palms to monitor and manage the WCLWD in the Southern Province. It was hypothesized that the successful identification of affected palms or at least areas with heavy infestation with more prominent leaf yellowing, would lead to ground surveillance in areas which required more vigilance.

\section{MATERIAL AND METHODS}

\section{Images and image processing}

High resolution $(0.5 \mathrm{~m}$ resolution) satellite images of $170 \mathrm{~km}^{2}$ area,covering Galle, Matara and Hambantota districts, where the WCLWD was prevalent, were purchased. The satellite images were in two strips as shown in Fig. 5. These images had been captured by the USA launched GEOEYE satellite and contained both panchromatic (black and white) and multispectral (blue, green, red and near InfraRed) bands with $0.5 \mathrm{~m}$ resolution.

Ground coordinates to include 250 coconut palms were taken in over seven different locations namely, Batadolawatta in Kekunadora, Medahenawatta in Rathmale, Miriswatta in Beliatta, Muruthagaspitiya in Ihalaboda, Yayawaththa in Urugamuwa and Dodampahala in Nilwella (Fig. 6). Ground coordinates of affected palms in different stages of severity of WCLWD were taken.

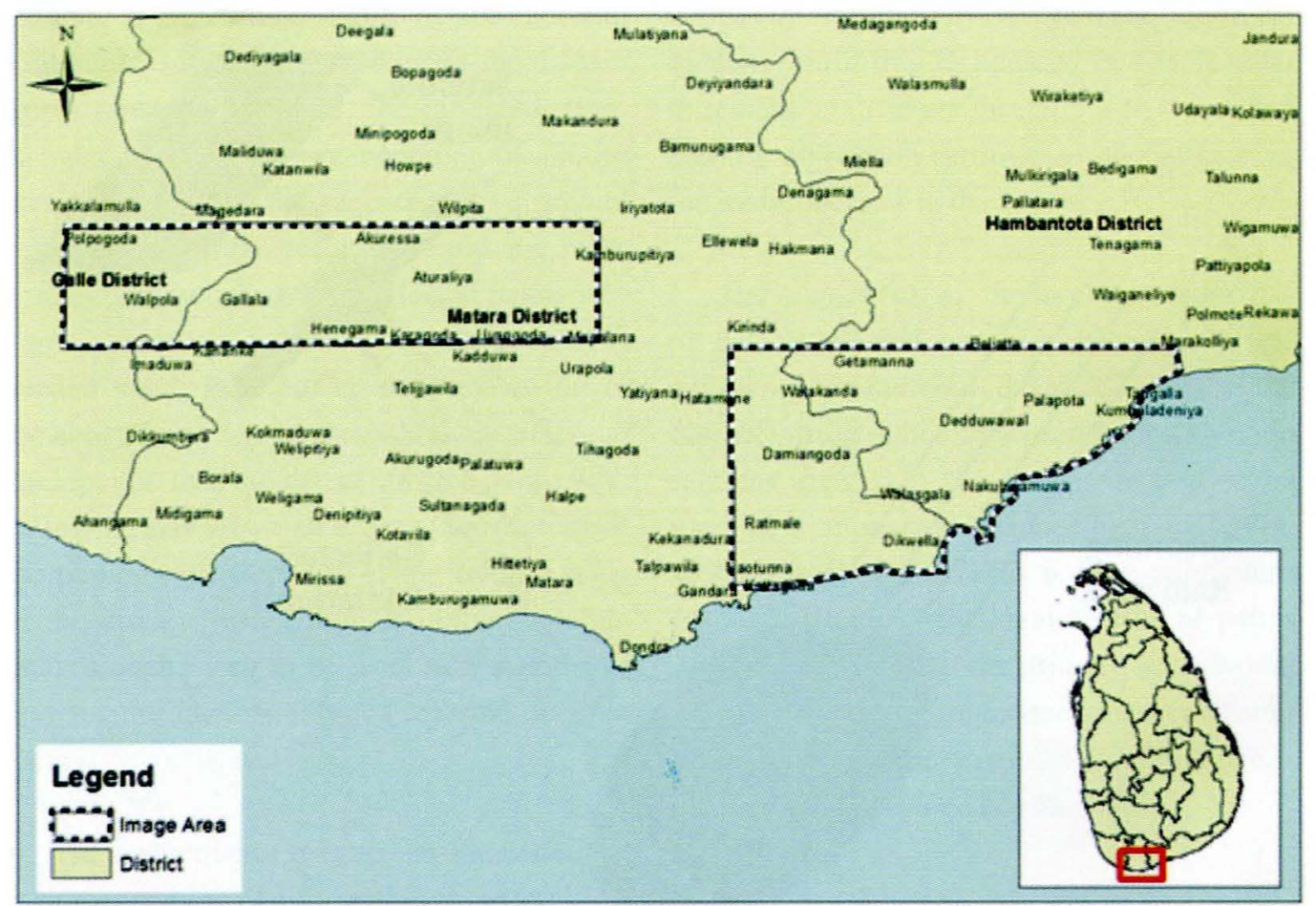

Fig. 5. Map showing satellite images covering an area of $170 \mathrm{~km}^{2}$ in two strips in disease prevalent areas. 


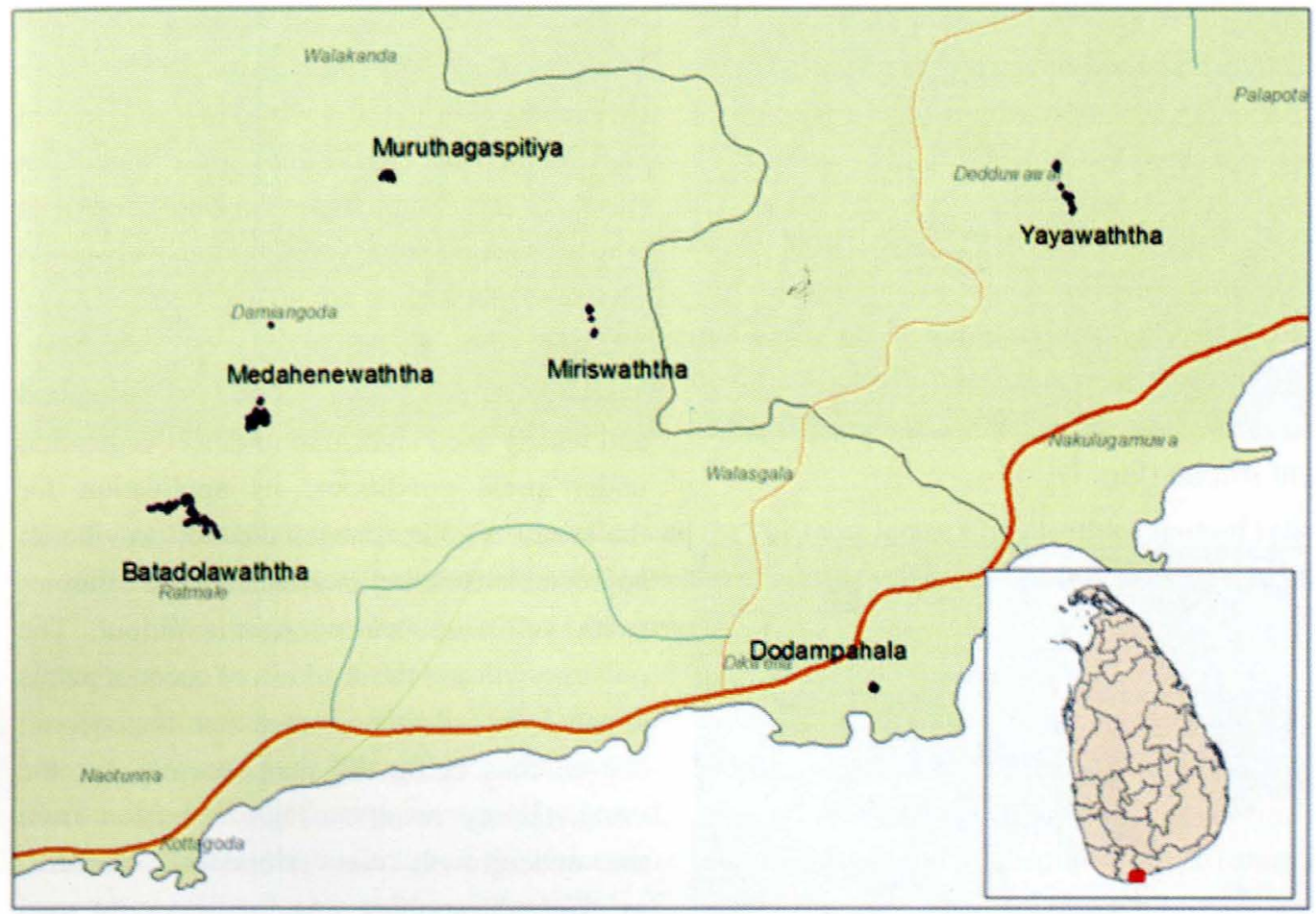

Fig. 6. Map showing seven different sample locations for GPS coordinates used in the survey.

It included palms with flaccidity only, flaccidity with slight leaf yellowing, flaccidity with prominent leaf yellowing, intensely yellowish coconut canopies, palms showing all three symptoms in different combinations (flaccidity, leaf yellowing and necrosis), leaf rot affected palms with different severity stages and apparently healthy palms. Ground coordinates of king coconut palms in the vicinity were also taken to test the possibility of excluding king coconut palms which are misleading due to the slight yellowish colour of their canopies. Of the above sites, Medahenawatta and Muruthagaspitiya were severely affected with palms showing intense yellowing and Batadolawaththa was slightly affected. Affected palms were in sporadic patches in other locations.

Analysis of remote sensing data for spectral patterns and development of a classification programme (Image Processing) were conducted using Eardas 9.2 computer software. The process was conducted in several steps with ground truthing to confirm relevant identifications. Images were in four colour bands combined for different compositions and pan sharpened to enhance the resolution. A specific colour composition, which is generally used for vegetation, such as Normalized Differential Vegetation Index (NDVI) was calculated using red and near IR (NIR) bands for different spectral resolutions. The results obtained were cross referenced with GPS coordinates obtained for affected palms during ground truthing. NDVI is a standard algorithm, which is widely used around the world to detect stressed vegetation leaves. Image algebra was used to enhance the images by removing shadows and to minimize the interference from 
underground covers. In addition, many other customized algorithms were tested using image calculators, for the detection of yellow coloured coconut canopies.

Further verification of these results with a different satellite image of same resolution was tested by applying the same algorithm to four other locations with infected palms in Boralawewa, Midigama, Muruthagaspitiya and Wilpita (Fig. 7).

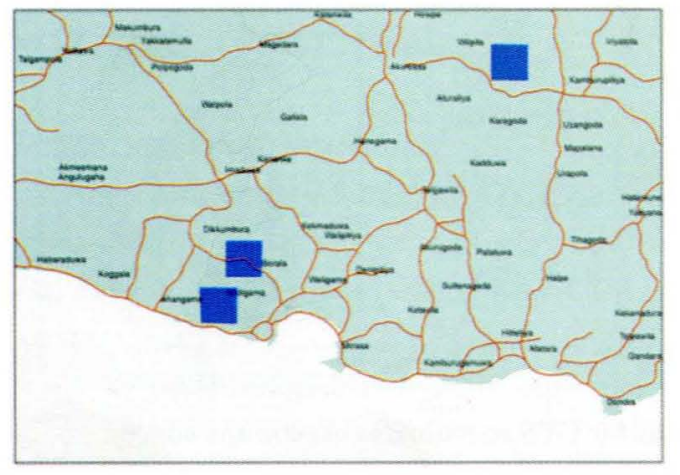

Fig. 7. Map showing sample locations used for the confirmation of WCLWD disease prevalence

\section{RESULTS AND DISCUSSION}

Satellite-derived drought indices typically use observations in multispectral bands, which provide different information about surface conditions. As meteorological and soil conditions are naturally associated with vegetation state and cover, vegetation indices (VIs) are commonly used for such studies. The most commonly used VI is the Normalized Difference Vegetation Index (NDVI), which is based on the difference between the maximum absorption of radiation in red ( $\mathrm{R})$ as a result of chlorophyll pigments and the maximum reflectance in near Infra-red (NIR) spectral region as a result of leaf cellular structure (Tucker, 1979). NDVI has widely been used to evaluate the performance of different crops such as wheat (Benedetti and Rossini, 1993), maize (Mkhabela et al., 2005), winter wheat (Hansen and Schjoerring, 2003) and forest vegetation (Pisek et al., 2015) under varying conditions while its applicability has extensively been reviewed (Karnieli et al., 2010).

Although the NDVI is one of the standard and widely used algorithm to detect vegetation under stress conditions, its application for the tested satellite images did not provide an appreciable isolation of affected palm canopies (with yellowish leaves) in the output. The undergrowth and the shadows of coconut palms dictated the reflectance more than the coconut leaves, thus being the main reasons for the unsatisfactory results. Thus reflection from the undergrowth was erroneously detected as affected canopies. As the generally used algorithms did not result in the expected performance, many other customized algorithms were tested using image calculators, for the detection of yellow coloured coconut canopies. The best outcome among them was obtained by following the algorithm [(Red + Green) $-2 x$ (Blue)]. The detection of affected coconut palms in one of the satellite images is shown in Fig. 8.

Number of palms detected using image processing under the three different categories of varying intensities of symptoms was tested against the number of damaged palms detected by the naked eye using morphological symptoms. The level of accuracy of the detection of affected palms was at a substantial level in the three categories viz. palms with intense yellowing, palms with yellowing and flaccidity and leaf rot affected palms, in almost all sample sites tested. 


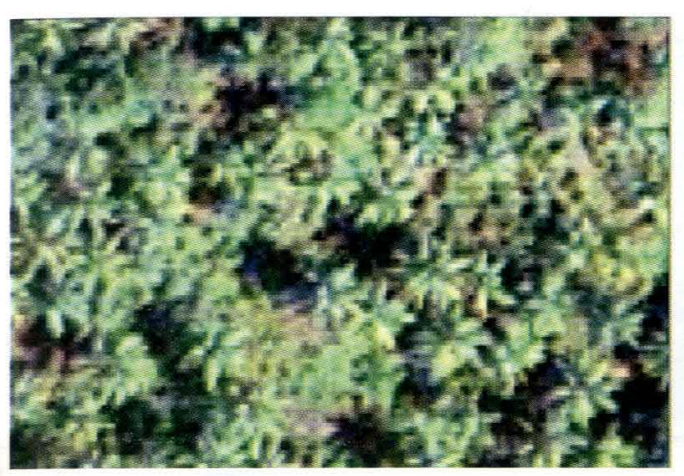

a

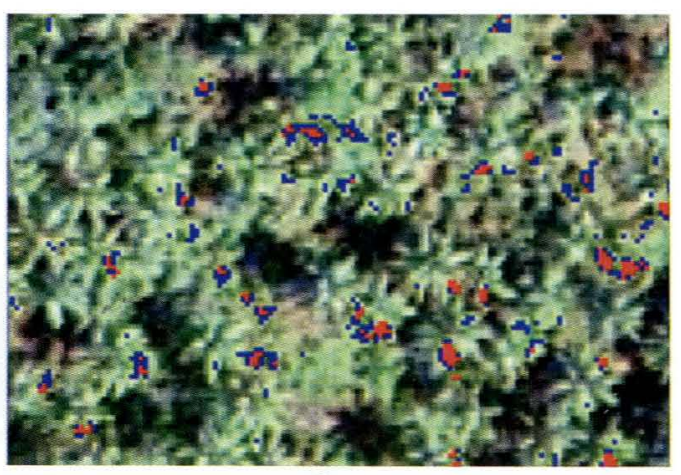

b

Fig. 8. (a) The satellite image of a given location and (b) The same image with identified spots of yellow coloured pixels (Pixels marked with red colour represent yellowed segments and pixels in blue colour represent slightly yellowed segments).

Sample coconut palm patches in Medahenawatta and Muruthagaspitiya where the numbers and the intensities were higher and more prominent, the accuracy of the detection was higher (Fig. 9a). In palms with which leaf yellowing at a very intensive level and leaf rot conditions, detection was much more accurate and promising. However, the level of accuracy in detecting palms with slight yellowing or the leaf flaccidity which are the initial symptoms of the disease, was not at an acceptable level for field applications. Moreover, the differentiation of king coconut palms, which are rather sporadic but abundant in the Southern province, from the rest of palms was not really successful (Fig. 9a). A greater problem was encountered in the seedling stage of coconut as their canopies were relatively small in size while they were partially or fully covered by adult coconut canopies or other tree canopies in the estate in most instances. Thus the detection accuracy dropped drastically in seedlings (Fig. 9 b). The accuracy levels of detection in different damage categories of palms were comparable to other sample sites and results of some sites are shown in Fig. 10.
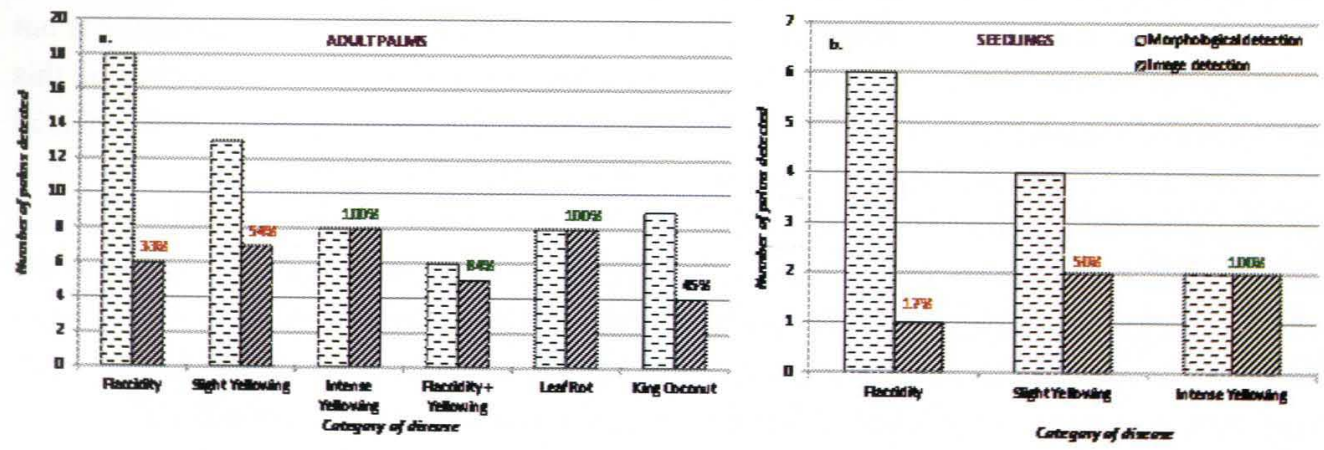

Fig. 9. Palms in sample patches in Medahenwatta with disease symptoms in different categories detected using morphological symptoms and image processing (a) in adult palms and (b) in seedling stage. [Level of accuracy indicated as a \%]. 

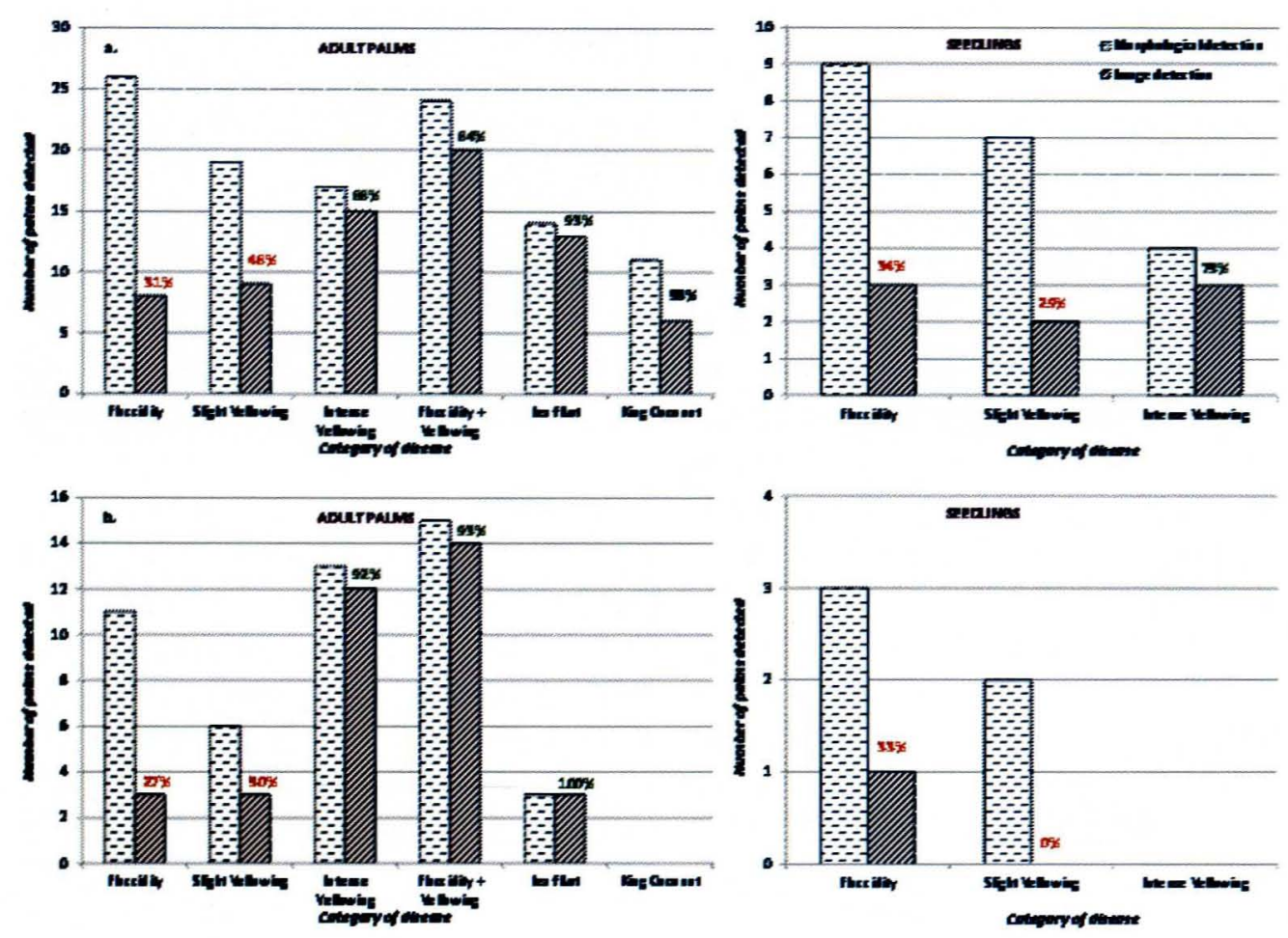

Fig. 10. Palms detected in sample patches in (a) Batadolawatta and (b) Yayawattain different disease symptom categories detected using morphological symptoms and image processing (a) adult palms and (b) seedlings. [Level of accuracy indicated as a \%].

Overall, detection of WCLWD affected adult palms in advanced stages could be made using satellite image processing technology with about $80 \%$ accuracy. In lands with organized coconut planting systems and in monocrop cultivations (coconut only), detection of affected palms would be much easier and results are more accurate with satellite images of $0.5 \mathrm{~m}$ resolution. However, detection at the initial stages of the disease (where flattening of leaflets with distal end of leaflets bending down (flaccidity) with slight yellowish colour in coconut canopy) could not be improved beyond $40 \%$ accuracy. Appreciable level of detection of disease symptoms in the seedling stage could not be achieved with the existing resolution of multispectral satellite images. This was mainly due to the small canopy structure of seedlings and also due to the shading of seedlings by adult coconut canopies and / or other tall canopies. Thus the overall accuracy that could be achieved remained between 60 to $70 \%$ with multispectral satellite images of $0.5 \mathrm{~m}$ resolution. This level of accuracy is not sufficient for a field level application of this technology for detecting WCLWD affected palms in the Southern Province. This was mainly due to the inherent limitations in the currently available methodology. However the methodology is likely to improve in the future month the advancement of the technology. The primary requirement of multispectral satellite images of higher resolution, $0.2 \mathrm{~m}$ or above is currently limited to the defense related institutions and not for commercial or other activities. 


\section{CONCLUSIONS}

Normalized Differential Vegetation Index (NDVI) which is the standard and widely used algorithm to detect vegetation under stress conditions did not reveal an appreciable isolation of affected palm canopies. The best outcome was obtained by a customized algorithm of (Red + Green) -2 $x$ (Blue). Advanced stages of affected adult coconut palms could be isolated from the rest of coconut palms with above $80 \%$ accuracy using multispectral satellite images of $0.5 \mathrm{~m}$ resolution. However, precise detection of palms at early stages of disease where leaf flaccidity is the major symptom could not be achieved with substantial accuracy. Detection of disease symptoms in coconut seedlings was much more difficult. Therefore, the overall accuracy of detection including all stages of damages that could be achieved was around 60 to $70 \%$ with multispectral satellite images of $0.5 \mathrm{~m}$ resolution.

\section{ACKNOWLEDGEMENT}

This project was funded by the Food and Agriculture Organization of United Nations under the FAO-TCP project TCP/ SRL/3303. The support extended by Dr. D. S. P. Kuruppuarachchi, Assistant Representative (Programs) of the UNDP office in Sri Lanka is acknowledged. Technical assistance extended during ground truthing activities by Mr. D. I. Jayalath and Ms. V. N. Thembiliyagoda of the Department of Geology, Faculty of Science, University of Peradeniya is acknowledged.

\section{REFERENCES}

Anon. (1949). Report of the coconut commission, Ceylon.

Benedetti, R. and Rossini, P. (1993). On the use of NDVI profiles as a tool for agricultural statistics: The case study of wheat yield estimate and forecast in Emilia Romagna. Remote Sensing of Environment, 45 (3), 311-326.

Census and Statistics. (2002). Sri Lanka Census of Agriculture. Department of Census and Statistics, Sri Lanka.

Child, R. (1974). Coconut. $2^{\text {nd }}$ Edition. Longman Green ann Co.

Everard, J. M. D. T. (2013). Integrated management of Weligama coconut leaf wilt disease program in Sri Lanka: Strategies, implementation and challenges In: Weligama Coconut Leaf Wilt Disease Six years after (Eds. H. P. M. Gunasena, H. A. J. Gunathilake, L. C. P. Fernando, J. M. D. T. Everard and P. A. H. N. Appuhamy) pp. 13-17, Coconut Research Institute, Sri Lanka.

Hansen, P. M. and Schjoerring, J. K. (2003). Reflectance measurement of canopy biomass and nitrogen status in wheat crops using normalized difference vegetation indices and partial least square regression. Remote Sensing of Environment, 86 (4), 542-553. 
Karnieli, A., Agam, N., Pinker, R. T., Anderson, M., Imhoff, M. L., Gutman, G. G., Panov, N. and Goldberg, A. (2010). Use of NDVI and Land Surface Temperature for drought assessment: Merits and limitations. J. of Climate, 23, 618-633.

Kumara, A. D. N. T., Aratchige, N. S. and Fernando, L. C. P. (2013). Vectors of Weligama coconut leaf wilt disease In: Weligama Coconut Leaf Wilt Disease Six years after (Eds. H. P. M. Gunasena, H. A. J. Gunathilake, L. C. P. Fernando, J. M. D. T. Everard and P. A. H. N. Appuhamy)pp. 26-30, Coconut Research Institute, Sri Lanka.

Mkhabela, M. S., Mkhabela Milton, S. and Mashinini, N. N. (2005). Early maize yield forecasing in the four agro-ecological regions of Swaziland using NDVI data derived from NOAA'sAVHRR. Agricultural and Forest Meteorology, 129 (1-2), 1-9.

Nainanayake, A. D and Ranasinghe, C. S. (2013). Physiological / biochemical effects of WCLWD on palm and its productionIn: Weligama Coconut Leaf Wilt Disease Six years after (Eds. H. P. M. Gunasena, H. A. J. Gunathilake, L. C. P. Fernando, J. M. D. T. Everard and P. A. H. N. Appuhamy) pp. 31-47, Coconut Research Institute, Sri Lanka.

Perera, L., Meegahakumbura, M. K., Wijesekara, H. T. R., Fernado, W. B. S. and Dickinson, M. J. (2012). A phytoplasma is associated with the Weligama coconut Leaf Wilt Disease in Sri Lanka. J. Plant Pathol. 94 (1): 205-209.

Pisek, J., Rautiainen, M., Nicopensius, M., Rabee, K. (2015). Estimation of seasonal dynamics of NDVI in northern forests using MODIS BRDF data: semi-empirical versus physicallybased approach. Remote Sensing of Environment, 163, 42-47.

Sasikala, M., Amma, B. S. K. and Rajagopal, V. (1998). Diagnosis in coconut root (wilt) disease (Eds. Nampoorthiti and Koshy, P. K.). Central Plantation Crop Research Institute, Kasaragod, 671.124, Kerala, India. 47-51.

Tucker, C. J. (1979). Red and photographic infrared linear combinations for monitoring vegetation. Remote Sensing of Environment, 8, 127-150.

Wijesekara, H. T. R. and Fernando, L. C. P. (2013). Symptoms and etiology of Weligama coconut leaf wilt disease In: Weligama Coconut Leaf Wilt Disease Six years after (Eds. H. P. M. Gunasena, H. A. J. Gunathilake, L. C. P. Fernando, J. M. D. T. Everard and P. A. H. N. Appuhamy) pp. 18-25, Coconut Research Institute, Sri Lanka. 